
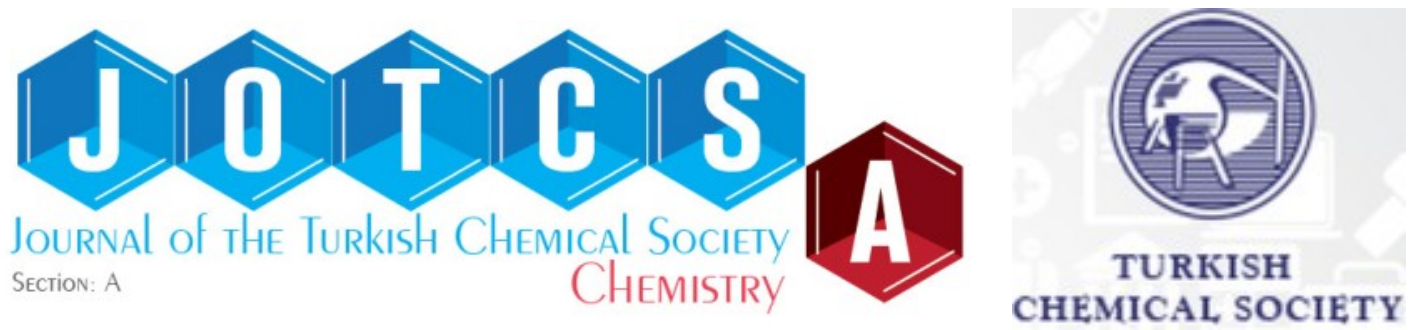

\title{
pH Effect on Hydrothermal Synthesis of the Coordination Polymers Containing Pyrazine-2,3-dicarboxylate: Investigation of Thermal Stability, Luminescence, and Electrical Conductivity Properties
}

\begin{abstract}
Burak AY ${ }^{1, *}$ QD, Emel YILDIZ ${ }^{1}$, JD, Jon ZUBIETA2
${ }^{1}$ Çukurova University, Arts and Science Faculty, Department of Chemistry, 01330, Adana, Turkey. ${ }^{2}$ Department of Chemistry, Syracuse University, Syracuse, NY 13244, USA.

Abstract: Hydrothermal reactions of the lanthanide(III) salt with 2,3-pyrazinedicarboxylic (2,3-pzdc) acid yielded the coordination polymers $\left[\mathrm{La}_{2}(2,3-\mathrm{pzdc})_{3}\left(\mathrm{H}_{2} \mathrm{O}\right)\right]_{n} \cdot 3 \mathrm{nH}_{2} \mathrm{O}$ (1) and $\left[\mathrm{La}_{2}(2,3-\right.$ pzdc $\left.)_{3}\left(\mathrm{H}_{2} \mathrm{O}\right)\right]_{n} .2 \mathrm{nH}_{2} \mathrm{O}(2)$. Compounds were obtained in a three dimensional form with different pH values under subcritical water conditions. The structures had variable coordination numbers. In addition, $\mathrm{pH}$ values play an important role in the structural chemistry of these materials. Different characterization techniques (elemental analysis, FT-IR, ICP-OES, TG/DTA, FESEM, PXRD, BET and single crystal X-ray) were carried out to confirm crystallinity, porosity, purity and chemical composition of the coordination polymers. Crystal structures of the polymers were examined in detail. Their thermal stability, luminescence and electrical conductivity properties were investigated in the solid state.
\end{abstract}

Keywords: pH effect, hydrothermal synthesis, lanthanum coordination polymer, electrical conductivity.

Submitted: May 15, 2019. Accepted: December 16, 2019.

Cite this: Ay B, Yıldız E, Zubieta J. pH Effect on Hydrothermal Synthesis of the Coordination Polymers Containing Pyrazine-2,3-dicarboxylate: Investigation of Thermal Stability, Luminescence, and Electrical Conductivity Properties. JOTCSA. 2020;7(1):243-58.

DOI: https://doi.org/10.18596/jotcsa.565700.

*Corresponding author. E-mail: bay@cu.edu.tr.

\section{INTRODUCTION}

Coordination polymers (CPs) have structures consisting of metal nodes and organic linkers that are connected together via coordination bonds (13). Synthesis of the CPs have attracted everincreasing interest not only their structural aesthetics but also their potential applications such as heterogeneous catalyst (4-6), luminescence (79), gas storage (10-12), molecular separation (13), sensor (14), drug encapsulation (15) and so on. Several methods have been used for the synthesis of CPs. Among them, some important synthetic routes are hydro/solvothermal synthesis, sonochemical, slow evaporation, microwave assisted synthesis, mechanochemical and electrochemical synthesis (16). It is well known that the crystallization, structure, and morphology of CPs depend on the metal or ligand type, solvent type (17-19), pH value of reaction mixture (2023), stoichiometric ratio of metal/ligand (24), mineralizing agent (25), temperature (26-28), and time (29). These parameters play a profound effect on the structural chemistry of compounds. In this study, $\mathrm{pH}$ effect of the solution on polymer formation under subcritical conditions was investigated. For this purpose, multifunctional 2,3pzdc was selected as a ligand due to the six potential coordination sites. There are many studies on the coordination modes of the 2,3-pzdc acid ligand in the literature. These modes are available in many different coordination modes, including mono-to-heptadentate and bridging mode ligands (30-42). However, the number of 
works with mixed coordination mode is very few (43). In this work, the ligand 2,3-pzdc adopted three different coordination modes in the polymeric chains through which lanthanum ions are linked together to form a three-dimensional structure.

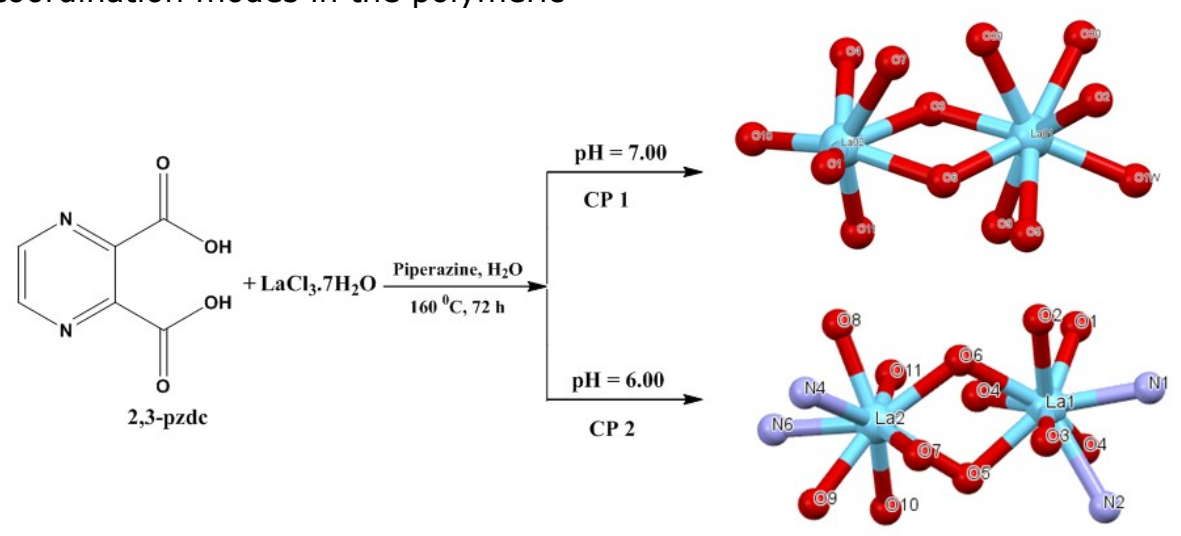

Figure 1: Schematic representation of CPs synthesized at different $\mathrm{pH}$ values in hydrothermal conditions.

In this work, our aim is hydrothermal synthesis of $\mathrm{CPs}$ to better understand the $\mathrm{pH}$ effect under subcritical conditions. In the synthesis of CPs, stoichiometric ratio, reaction temperature, and time were kept constant and $\mathrm{pH}$ values were changed from 1.00 to 7.00. $\mathrm{pH}$ values were adjusted by a mineralizing agent piperazine. At the $\mathrm{pH}$ values of 6.00 and 7.00, three dimensional lanthanum-based coordination polymers, namely $\left[\mathrm{La}_{2}(2,3-\mathrm{pzdc})_{3}\left(\mathrm{H}_{2} \mathrm{O}\right)\right]_{\mathrm{n}} \cdot 3 \mathrm{nH}_{2} \mathrm{O}$ (1) and $\left[\mathrm{La}_{2}(2,3-\right.$ pzdc $\left.)_{3}\left(\mathrm{H}_{2} \mathrm{O}\right)\right]_{n} .2 \mathrm{nH}_{2} \mathrm{O}$ (2), with different coordination numbers and coordination modes were obtained (Figure 1). Electrical conductivity, thermal stability, and luminescence properties of CPs were investigated.

\section{EXPERIMENTAL}

\section{Materials and methods}

All chemicals were purchased from commercial sources and used without further purification. PTFE-lined stainless steel containers with $23 \mathrm{~mL}$ capacity were used for hydrothermal synthesis. Perkin Elmer Pyris Diamond TG/DTA equipment (50-800 ${ }^{\circ} \mathrm{C}$ range) at a heating rate of $10 \mathrm{\circ} \mathrm{C} / \mathrm{min}$ was used for TGA analysis. Thermo Flash 2000 CHNS analyzer was used for the elemental analysis. Quantitative lanthanide analyses were performed with Perkin-Elmer Optima 2100DV Inductively Coupled Plasma Optical Emission Spectrometry (ICP-OES) instrument. Perkin-Elmer RX-1 FT-IR with $\mathrm{KBr}$ pellets spectrometer in the range of $4000-400 \mathrm{~cm}^{-1}$ was used for the IR analysis of the compounds. The Field Emission Scanning Electron Microscope (FESEM) images of the compounds were recorded using Carl Zeiss, SUPRA-55. Rigaku Miniflex system with CuKa radiation $(\lambda=1.54059 \AA)$ was used for the Powder X-Ray Diffraction (PXRD) studies. The electrical conductivity properties of the coordination polymers were determined by four-point probe method with an Electrometer Entek Electronic FPP-
470. Asimeto AS-105 digital micrometer was used for thickness measurements. Perkin-Elmer LS 55 Luminescence Spectrometer was used for the solid state fluorescence excitation and emission spectra. LEICA EZ4W stereo microscope was used for the high definition views of the CPs. Autosorb-6B surface area and pore size analyzer was used for the Brunauer, Emmett and Teller (BET) analysis.

Synthesis of $\left.\mathrm{La}_{2}(2,3-\mathrm{pzdc})_{3}\left(\mathrm{H}_{2} \mathrm{O}\right)\right]_{n} \cdot 3 \mathrm{nH}_{2} \mathrm{O}$ (1) A mixture of $\mathrm{LaCl}_{3} .7 \mathrm{H}_{2} \mathrm{O}(0.1114 \mathrm{~g}, 0.30 \mathrm{mmol})$, 2,3-pzdc acid $(0.0504 \mathrm{~g}, 0.30 \mathrm{mmol})$, piperazine $(0.0517 \mathrm{~g}, 0.60 \mathrm{mmol})$ and $\mathrm{H}_{2} \mathrm{O}(5.00 \mathrm{~mL}, 277.80$ $\mathrm{mmol})$ with the mole ratio of $1: 3: 3: 927$ were added $23 \mathrm{~mL}$ volumetric steel Parr Acid reactor. The heterogeneous solution was stirred for 30 minutes at ambient temperature. The white solution with an initial $\mathrm{pH}$ of 7.00 was heated at $160{ }^{\circ} \mathrm{C}$ for 72 hours. At the end of the reaction, the system was cooled to room temperature. The final $\mathrm{pH}$ of the solution was measured by separating the yellow solution and crystals $(\mathrm{pH}=$ $6.10)$. The resulting yellow crystals were washed with pure water and dried (Figure 2). Single crystals suitable for X-ray diffraction analysis were obtained in $78 \%$ yield. Anal. Calcd. for $\mathrm{C}_{18} \mathrm{H}_{18} \mathrm{~N}_{6} \mathrm{O}_{15} \mathrm{La}_{2}$ : C, 25.86; $\mathrm{H}, 2.17 ; \mathrm{N}, 10.05$. Found: C, 25.83; H, 2,08; N, 10.34\%. The ICPOES analysis (\%) showed that 1 contained La: 33.22; Calcd.: 34.17. IR ( $\mathrm{KBr}$ pellet, $\left.\mathrm{cm}^{-1}\right): 3500$, 3362 (m, b), $1618(\mathrm{~s}), 1558$ (s), $1366(\mathrm{~m}), 558$ (m), $442(\mathrm{~m})$. 


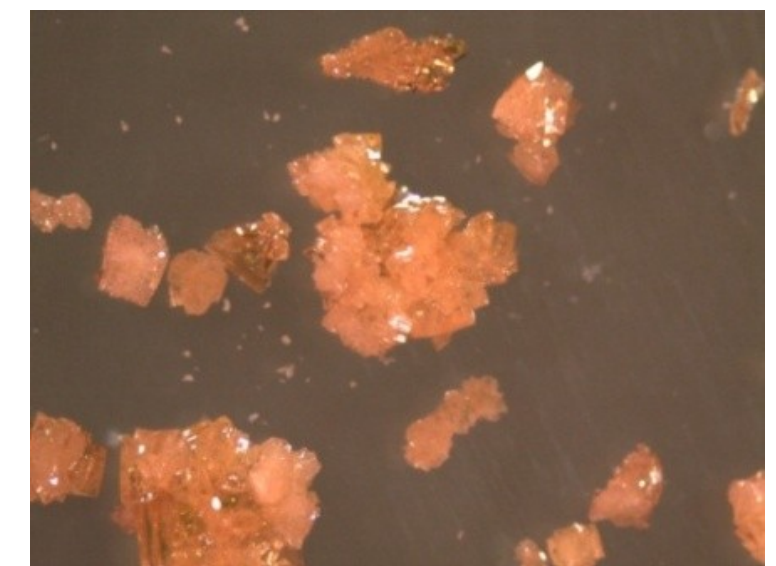

Figure 2: High resolution microscope image of $\mathbf{1}$ crystals.

\section{Synthesis of $\left[\mathrm{La}_{2}(2,3-\mathrm{pzdc})_{3}\left(\mathrm{H}_{2} \mathrm{O}\right)\right]_{\mathrm{n}} \cdot 2 \mathrm{nH}_{2} \mathrm{O}$ (2)}

A mixture of $\mathrm{LaCl}_{3} .7 \mathrm{H}_{2} \mathrm{O}(0.3714 \mathrm{~g}, 1.00 \mathrm{mmol})$, 2,3-pzdc acid $(0.1681 \mathrm{~g}, 1.00 \mathrm{mmol})$, piperazine $(0.1292 \mathrm{~g}, 1.50 \mathrm{mmol})$ and $\mathrm{H}_{2} \mathrm{O}(5.00 \mathrm{~mL}, 277.80$ $\mathrm{mmol}$ ) with the mole ratio of 1.00: 1.00: 1.50: 277.8 were added $23 \mathrm{~mL}$ volumetric steel Parr Acid reactor. The heterogeneous solution was stirred for 30 minutes at ambient temperature. The white solution with an initial $\mathrm{pH}$ of 6.00 was heated at $160{ }^{\circ} \mathrm{C}$ for 72 hours. At the end of the reaction, the system was cooled to room temperature. The final $\mathrm{pH}$ of the solution was measured by separating the yellow solution and crystals $(\mathrm{pH}=$ 5.30). The resulting light yellow crystals were washed with pure water, and dried (Figure 3). The single crystals suitable for $X$-ray diffraction analysis were obtained in $86.8 \%$ yield. Anal. Calcd. for $\mathrm{C}_{18} \mathrm{H}_{16} \mathrm{~N}_{6} \mathrm{O}_{14} \mathrm{La}_{2}$ : C, 26.42; $\mathrm{H}, 1.97 ; \mathrm{N}, 10.27$. Found: C, 26.91; H, 2,05; N, 9.87\%. The ICP-OES analysis (\%) showed that 2 contained La: 32.52; Calcd.: 33.45. IR ( $\mathrm{KBr}$ pellet, $\left.\mathrm{cm}^{-1}\right): 3494,3335$ (m, b), 1606 (s), 1557 (s), 1363 (vs), 556 (s), 434 (s).

\section{X-ray Crystallography}

A Bruker SMART system equipped with a CCD diffractometer at low temperature (100 K) using MoKa radiation (MoKa $=0.71073 \AA$ ) was used for the X-ray single-crystal analysis (44). The data were corrected for Lorentz and polarization effects, and absorption corrections were made using SADABS $(45,46)$. The structure solution and refinement were carried out using the SHELXLTL crystallographic (47) software package. The structure was solved by direct methods and the nonhydrogen atoms refined against $F^{2}$ anisotropically. Crystal data are summarized in Table 1, and selected bond distances and bond angles are given in Tables 2 and 3 . Full tables bond lengths and angles for CPs are available as Supplementary materials (Tables S1-S4).

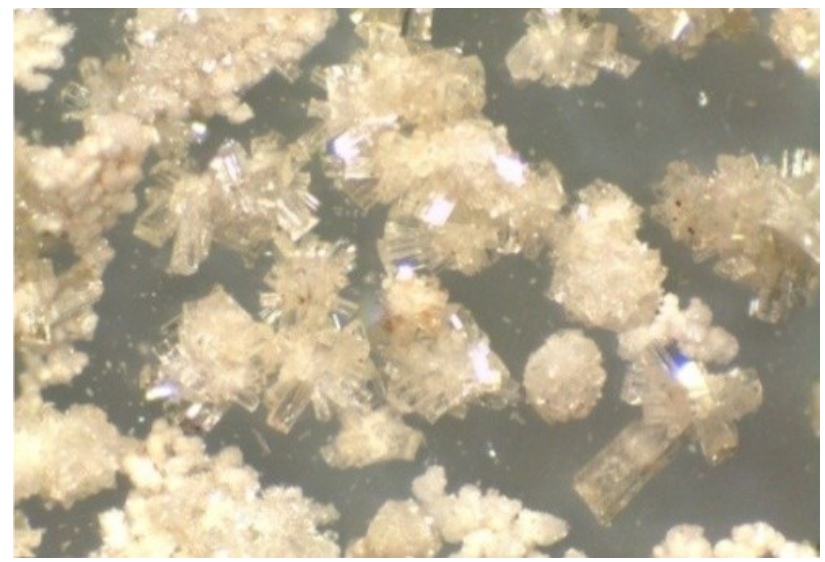

Figure 3: High resolution microscope image of $\mathbf{2}$ crystals.

\section{RESULTS AND DISCUSSION}

\section{Crystal structures of CPs}

Three-dimensional $\mathbf{1}$ and $\mathbf{2}$ have $\left[\mathrm{La}_{2}(2,3-\right.$ pzdc $\left.)_{3}\left(\mathrm{H}_{2} \mathrm{O}\right)\right]_{n} \cdot 3 \mathrm{nH}_{2} \mathrm{O}$ and $\left[\mathrm{La}_{2}(2,3-\right.$ pzdc $\left.)_{3}\left(\mathrm{H}_{2} \mathrm{O}\right)\right]_{\mathrm{n}} .2 \mathrm{nH}_{2} \mathrm{O}$ closed formulas. They have monoclinic $\mathrm{P} 2_{1} / \mathrm{c}$ crystal systems and these polymers differ from each other in terms of coordination modes and uncoordinated water molecules. Dimeric lanthanum atoms in $\mathbf{1}$ have trigonal prismatic geometry (seven coordination) and close to a trigonal dodecahedron (eight coordination) geometry, respectively. In $\mathbf{2}$, because of the $\mathrm{pH}$ effect of under hydrothermal conditions dimeric lanthanum atoms have tricapped trigonal prismatic geometry (nine coordination) (Figure 4). 


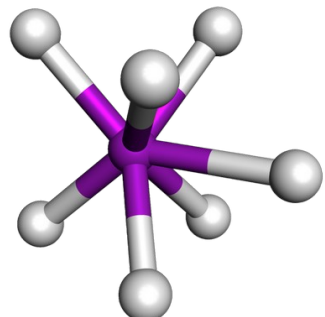

(a)

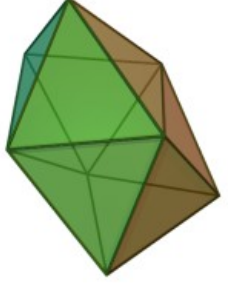

(b)

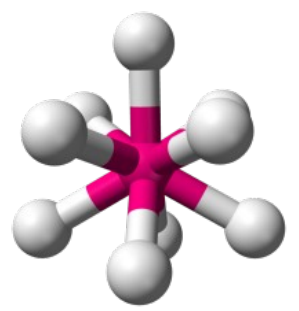

(c)

Figure 4: Trigonal prismatic geometry (a), trigonal dodecahedron (b) and tricapped trigonal prismatic geometry $(\mathbf{c})$.

Table 1. Crystal data and structure refinement for the CPs.

\begin{tabular}{|c|c|c|}
\hline Compound & $\mathbf{1}$ & 2 \\
\hline $\begin{array}{l}\text { Empirical Formula } \\
\text { Temperature (K) }\end{array}$ & $\begin{array}{l}\mathrm{C}_{18} \mathrm{H}_{18} \mathrm{~N}_{6} \mathrm{O}_{15} \mathrm{La}_{2} \\
100(2)\end{array}$ & $\begin{array}{l}\mathrm{C}_{18} \mathrm{H}_{16} \mathrm{~N}_{6} \mathrm{O}_{14} \mathrm{La}_{2} \\
100(2)\end{array}$ \\
\hline Formula weight & 836.20 & 818.16 \\
\hline Crystal system & Monoclinic & Monoclinic \\
\hline Space group & $\mathrm{P} 2_{1} / \mathrm{C}$ & $\mathrm{P} 2_{1} / \mathrm{c}$ \\
\hline $\mathbf{a}(\AA)$ & $8.9545(13)$ & $8.9637(3)$ \\
\hline b $(\AA)$ & $16.9040(3)$ & $16.9171(6)$ \\
\hline$c(\AA)$ & $15.468(2)$ & $15.4942(5)$ \\
\hline $\mathbf{a}\left({ }^{\circ}\right)$ & 90 & 90 \\
\hline$\beta\left({ }^{\circ}\right)$ & $101.348(2)$ & 101.36 \\
\hline$Y\left({ }^{\circ}\right)$ & 90 & 90 \\
\hline Volume $\left(\AA^{3}\right)$ & 2295.57 & 2303.51 \\
\hline $\mathbf{Z}$ & 4 & 4 \\
\hline Densitycalculated $\left(\mathrm{g} / \mathrm{cm}^{-3}\right)$ & 2.354 & 2.423 \\
\hline Absorp. coeff. $\left(\mu, \mathrm{mm}^{-1}\right)$ & 3.689 & 4.354 \\
\hline Wavelength $(\lambda, \AA)$ & 0.71073 & 0.71073 \\
\hline$R$ indices (all data) (R1 / wR2) & $0.0150 / 0.0489$ & $0.0332 / 0.0545$ \\
\hline
\end{tabular}

Single crystal X-ray analysis showed that 2,3-pzdc ligands show multiple chelation at 7.00 and 6.00 $\mathrm{pH}$ values. When the $\mathrm{pH}$ of the solution was adjusted to 7.00, during synthesis of $\mathbf{1}, 2,3-p z d c$ ligand behaved as 3, 5 and 6 dentate ligands in the polymeric chains (Figure 5). Due to the differences in the number of coordination modes in the frameworks, multiple metal bridges occurred.<smiles>OC(O[Ga])c1nccnc1C(O[Ga])O[Ga]</smiles>

Tridentate a) $\mu_{3}-\eta^{1}: \eta^{1}: \eta^{1}$<smiles>CCCCCCOC(O[Ga])c1nccnc1C(O[Ga])O[Ga]</smiles>

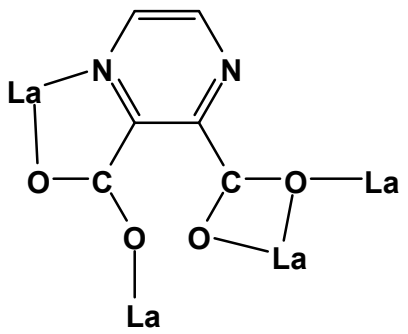

Pentadentate

b) $\mu_{5}-\eta^{1}: \eta^{1}: \eta^{1}: \eta^{2}$
Hexadentate

c) $\mu_{4}-\eta^{1}: \eta^{1}: \eta^{1}: \eta^{1}: \eta^{2}$

Figure 5: Coordinating modes of the 2,3-pzdc ligand at $\mathrm{pH}=7.00$ in compound $\mathbf{1}$.

Asymmetric units contain two La(III) ions. The La01 atom has eight coordination, while La02 atom of seven and together form a dimeric unit (Figure $6)$. As seen in the asymmetric unit of $\mathbf{1}$, nitrogen atoms of 2,3-pzdc ligand are not coordinated to metals in the case of $\mathrm{pH}$ at 7.00. Only oxygen atoms in the carboxyl groups are coordinated to metals. La01 and La02 atoms are linked to each other by oxygen bridges [(030)]. Around the La01 atom, five oxygen atoms from carboxyl groups, two oxygen bridges and with an oxygen atom in a coordinated water molecule, has totally eight coordination numbers. Nevertheless, there are a total of seven coordination numbers with the five 
oxygen atoms and two oxygen bridges from the carboxyl groups around around the La02 atom.
Asymmetric unit of $\mathbf{1}$, there are three water molecules outside the coordination sphere.

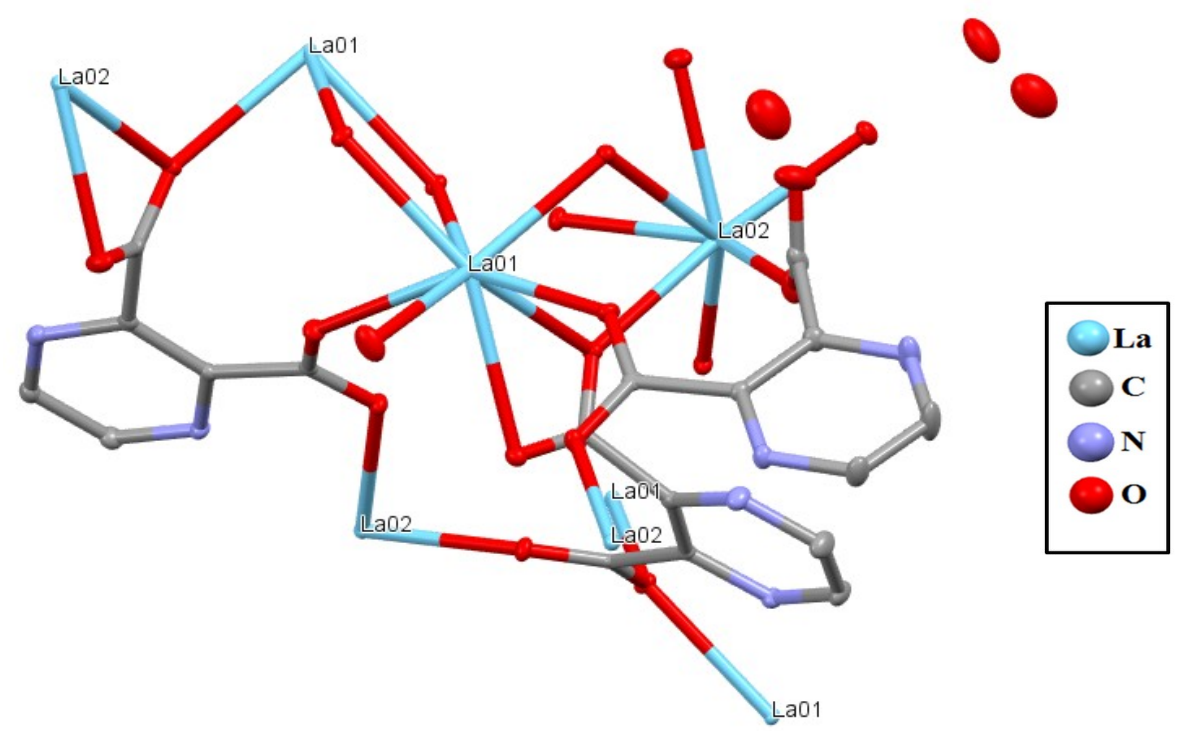

Figure 6: Coordination environment of different coordinated La(III) monomeric structure of $\mathbf{1}$. All hydrogen atoms are omitted for clarity.

Figure 7 shows the coordination environment of $\mathbf{1}$. La01 atom has eight coordination numbers and only oxygen atoms are coordinated to lanthanum atom. An oxygen atom [(09)] of the tridentate ligand, oxygen atoms [(03), (02)] of the pentadentate ligand, oxygen atoms [(O5), (06)] of the hexadentate ligand, oxygen atom of a coordinated water molecule $[(\mathrm{O} 1 \mathrm{~W})]$ and oxygen atoms in the bridge position are coordinated. However, La02 atom has a coordination number of seven. Oxygen atoms [(03), (04)] of the pentadentate ligand, oxygen atoms [(010), (011)] of the tridentate ligands, an oxygen atom [(06)] of the hexadentate ligand, and two oxygen atoms in the bridge position are coordinated. [(03), (06)] oxygen atoms coordinated to $\mathrm{La}$ (III) atoms and caused different structural positioning in the polymeric chain. La-O's bond lengths ranged from 2.396 to $2.695 \AA$, while O-La-O's bond angles are between 69.24 and $145.20^{\circ}$. The selected bond length and bond angle values of the atoms around the coordination sphere are given in Tables 2 and 3. 


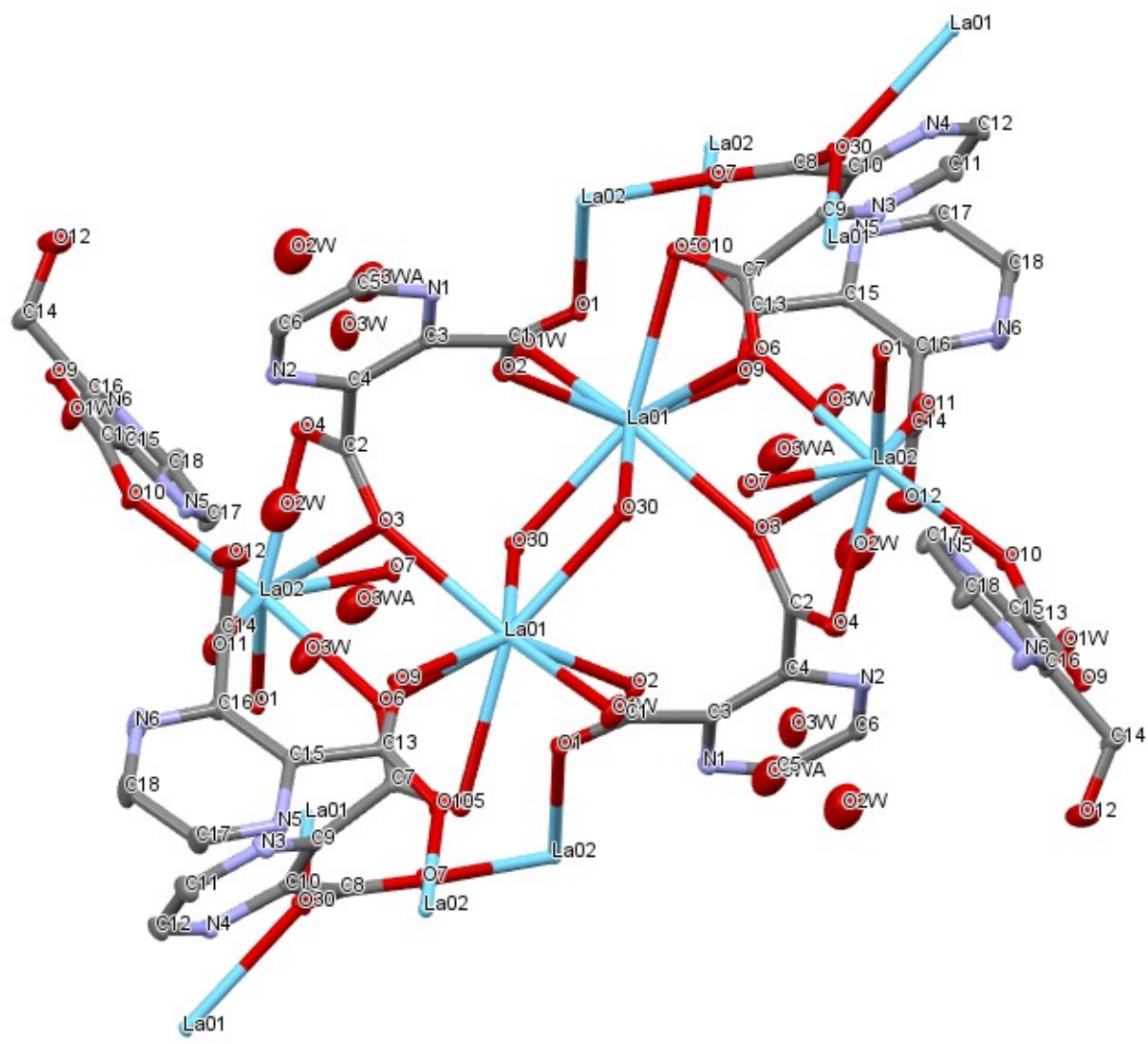

(a)

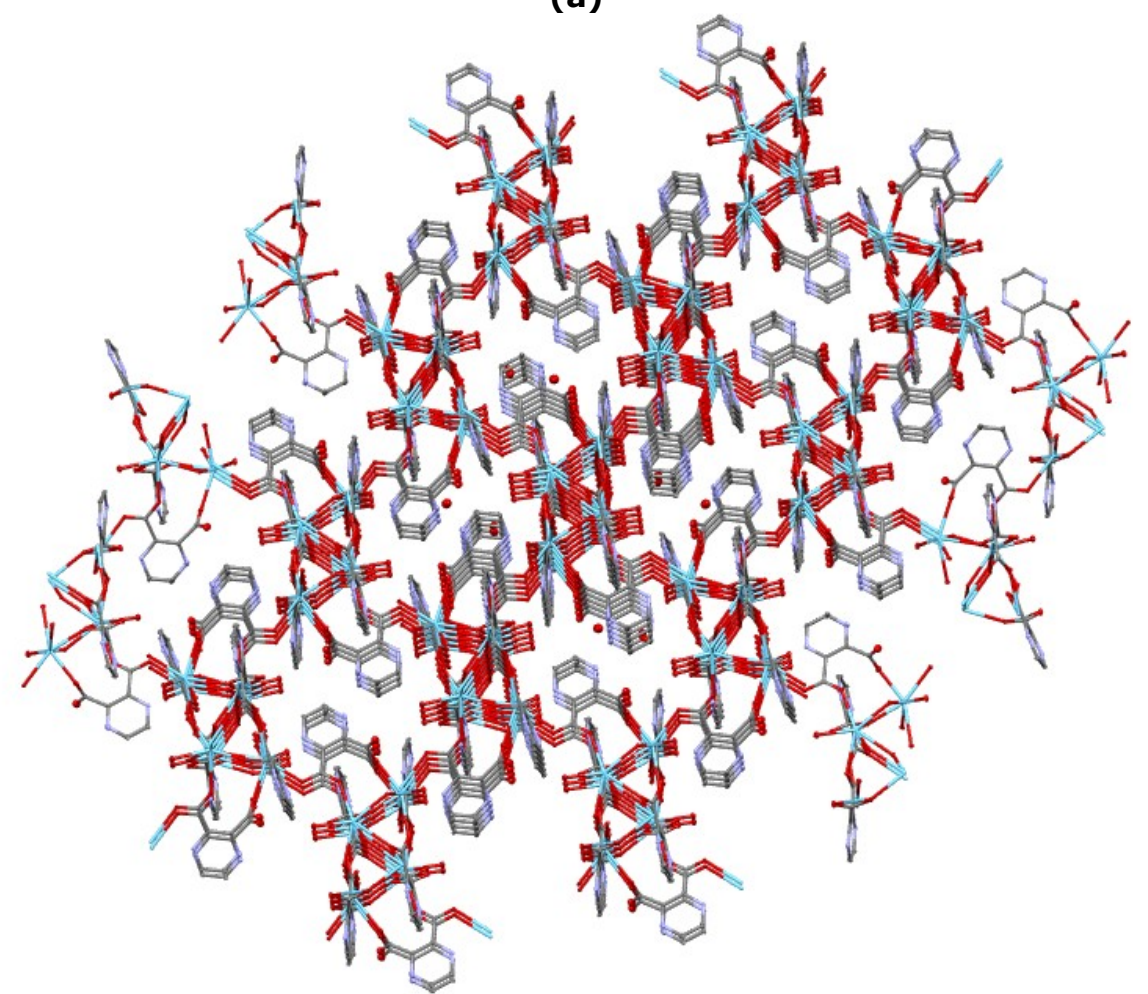

(b)

Figure 7: Coordination environment of the $\mathbf{1}$ (a) and 3D packing diagram linked by tridentate, pentadentate and hexadentate pzdc ligands (b). All hydrogen atoms are omitted for clarity. 
The $\mathrm{pH}$ of the solution was adjusted to 6.00 in the synthesis of $\mathbf{2}$. The 2,3-pzdc ligands behaved as 4-, 6-, and 7-dentate ligands in the polymer chain of $\mathbf{2}$ and showed differences from $\mathbf{1}$ (Figure 8).
Asymmetric units have two La(III) ions and both of them have a coordination number of 9 . The asymmetric unit consist of three 2,3-pzdc ligands with different coordination modes (Figure 9).<smiles></smiles>

Hexadentate<smiles>[Ga]OC1C2=NC=CN3[Ga]OC(O[Ge])C213</smiles>

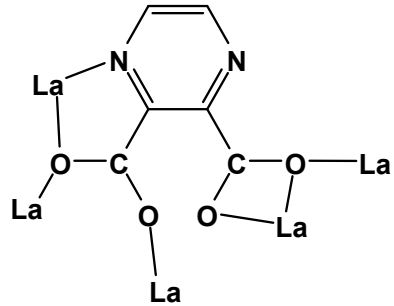

Heptadentate
a) $\mu_{3}-\eta^{1}: \eta^{1}: \eta^{1}: \eta^{1}$
b) $\mu_{4}-\eta^{1}: \eta^{1}: \eta^{1}: \eta^{1}: \eta^{2}$
c) $\mu_{5}-\eta^{1}: \eta^{2}: \eta^{1}: \eta^{1}: \eta^{2}$

Figure 8: The coordination modes of the 2,3-pzdc ligand at $\mathrm{pH}=6.00$ in the 2 .

Unlike 1, the nitrogen and oxygen atoms are also coordinated to metal atoms due to the $\mathrm{pH}$ value in the polymeric 2 . Two water molecules in monomeric structure are in the cage structure with hydrogen bonds outside the coordination sphere.
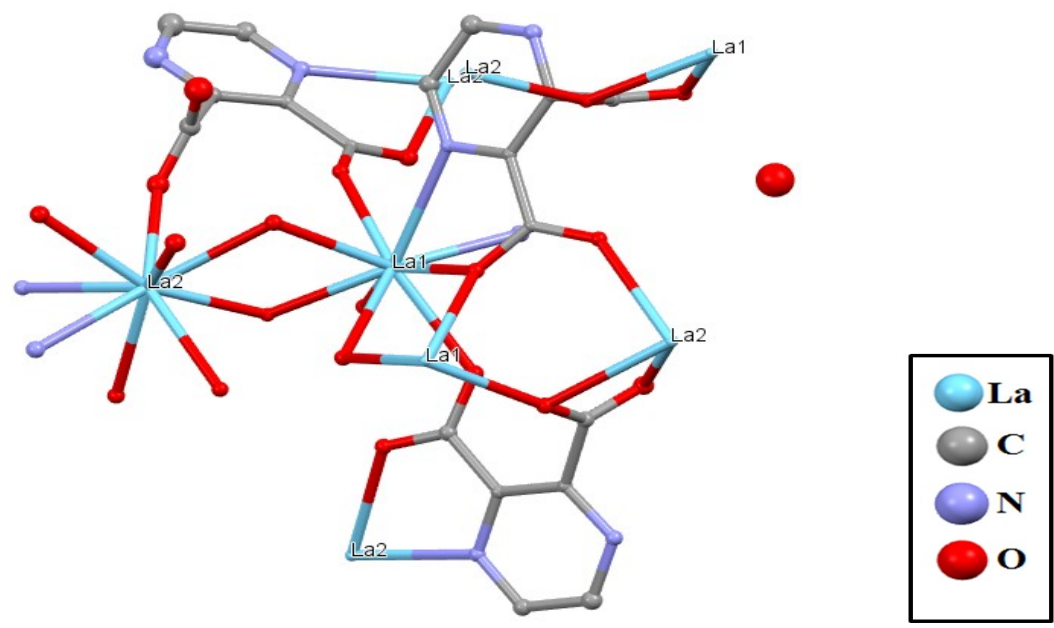

Figure 9: Coordination environment of nine coordinated monomer structures of 2. All hydrogen atoms are omitted for clarity.

Table 2. Selected bond length $[\AA]$ and bond angles $\left[{ }^{\circ}\right]$ for $\mathbf{1}$.

\begin{tabular}{llll}
\hline La01-O1W & $2.515(2)$ & La02-O1 & $2.503(1)$ \\
La02-O6 & $2.496(1)$ & La02-O10 & $2.491(2)$ \\
La01-O2 & $2.494(2)$ & La02-O11 & $2.396(2)$ \\
La01-O5 & $2.713(1)$ & La01-O9 & $2.442(1)$ \\
La01-O6 & $2.572(2)$ & La02-O7 & $2.565(1)$ \\
La02-O4 & $2.606(1)$ & La01-O3 & $2.536(2)$ \\
La02-O3 & $2.695(2)$ & La01-O30 & $2.628(1)$ \\
& & & $79.28(5)$ \\
O1W-La01-O2 & $73.28(5)$ & O1W-La01-O5 & $83.35(5)$ \\
O1W-La01-O6 & $128.29(5)$ & O1W-La01-O9 & $83.93(5)$ \\
O1W-La01-O3 & $145.20(5)$ & O1W-La01-O30 & $79.66(5)$ \\
O1W-La01-O30 & $137.69(5)$ & O2-La01-O5 & $144.04(5)$ \\
O2-La01-O6 & $98.25(5)$ & O2-La01-O9 & $73.01(5)$ \\
O2-La01-O3 & $138.33(5)$ & O2-La01-O30 & $49.24(5)$ \\
O2-La01-O30 & $69.45(5)$ & O5-La01-O6 & $114.88(5)$ \\
O5-La01-O9 & $69.24(5)$ & O5-La01-O3 & \\
\hline
\end{tabular}


There are three different coordination modes of the bridge 2,3-pzdc ligands in the polymeric chain (Figure 10), and the pyrazine rings are oriented in different ways in the framework. Although lanthanum ions have nine coordination number, coordination environments are different. The pzdc ligand, acting as hexa- and hepta-dentate, was coordinated to the lanthanum atom by the nitrogen $[\mathrm{N}(2)]$ and the oxygen $[\mathrm{O}(4)]$ atoms in the carboxyl group. Two oxygen atoms $[O(1), O(5)]$ in the carboxyl group $\left(\mu^{2}, n^{3}\right.$-carboxyl) of the hexadentate pzdc ligand, an oxygen [O(3)] atom in the carboxyl group of the tetradentate ligand, an oxygen $[\mathrm{O}(11)]$ atom in the $\mu^{2}, n^{2}$-carboxyl group of the heptadentate pzdc ligand and an oxygen $[\mathrm{O}(4)]$ atom in the $\mu^{2}, \eta^{3}$-carboxyl group of the other heptadentate pzdc ligand was coordinated to the La1 atom. Compared to La1, there is only one pzdc ligand that acts just like a heptadentate ligand around the coordination of La2 atom. La2 atom was coordinated through nitrogen and oxygen atom in the carboxyl group. La2 was also coordinated from two oxygen atoms in the carboxyl group of the heptadentate pzdc ligand and four oxygen atoms from the 4-, 6-, and 7dentate ligands. The oxygen atom from a water molecule coordinated by lanthanum centers and has completed nine coordination numbers. In total, six pzdc ligands are linked to the lanthanum ions. La-O's bond lengths ranged from 2.403 to $2.713 \AA$, while La-N's bond lengths were 2.531 and $2.767 \AA$. When the bond angles were examined, it was determined that O-La-O, O-La-N and N-La-N angles were between 69.2 and $144.1^{\circ}$, respectively, which are consistent with those of reported literature $(48,49)$.

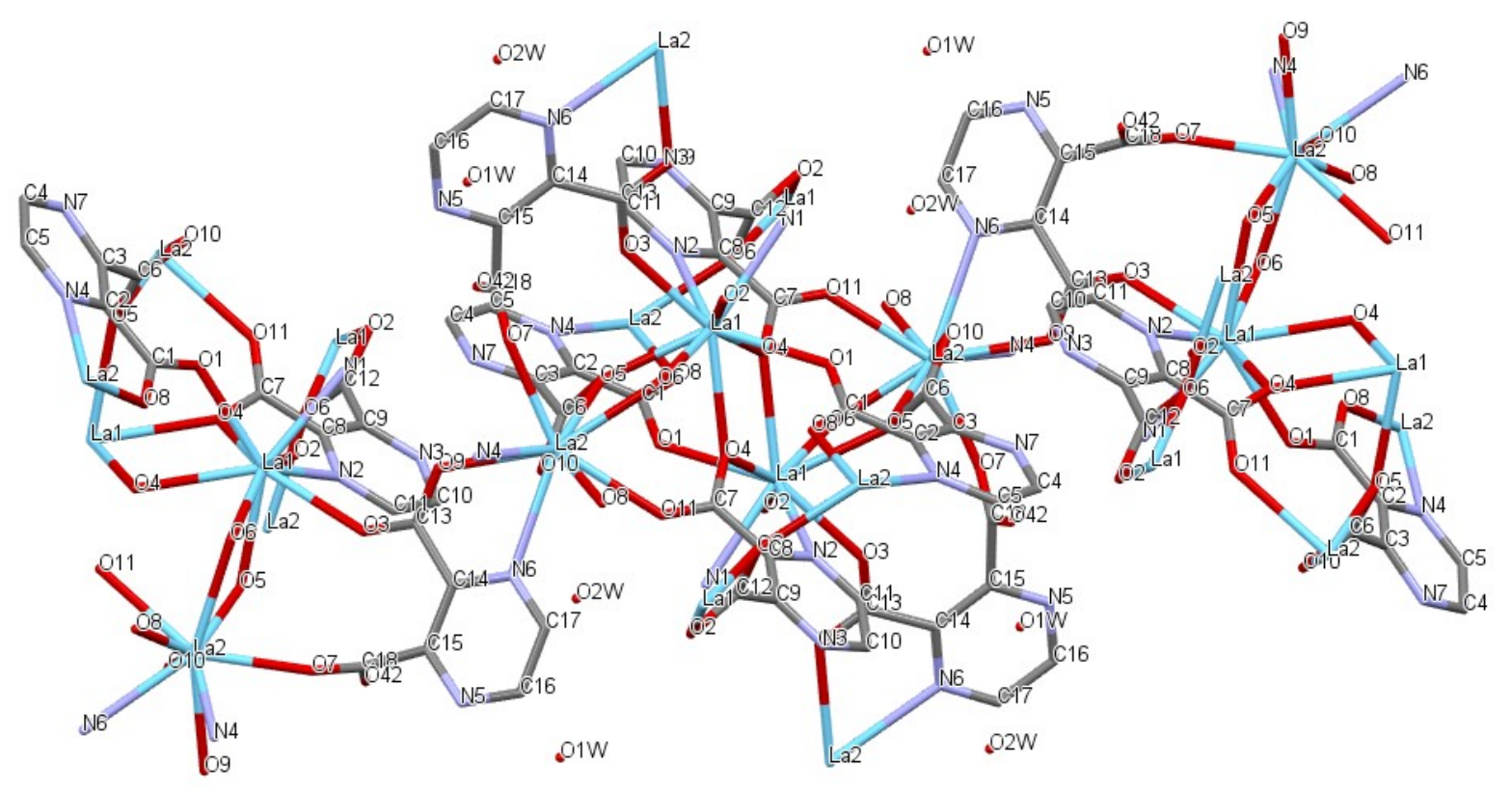

(a) 


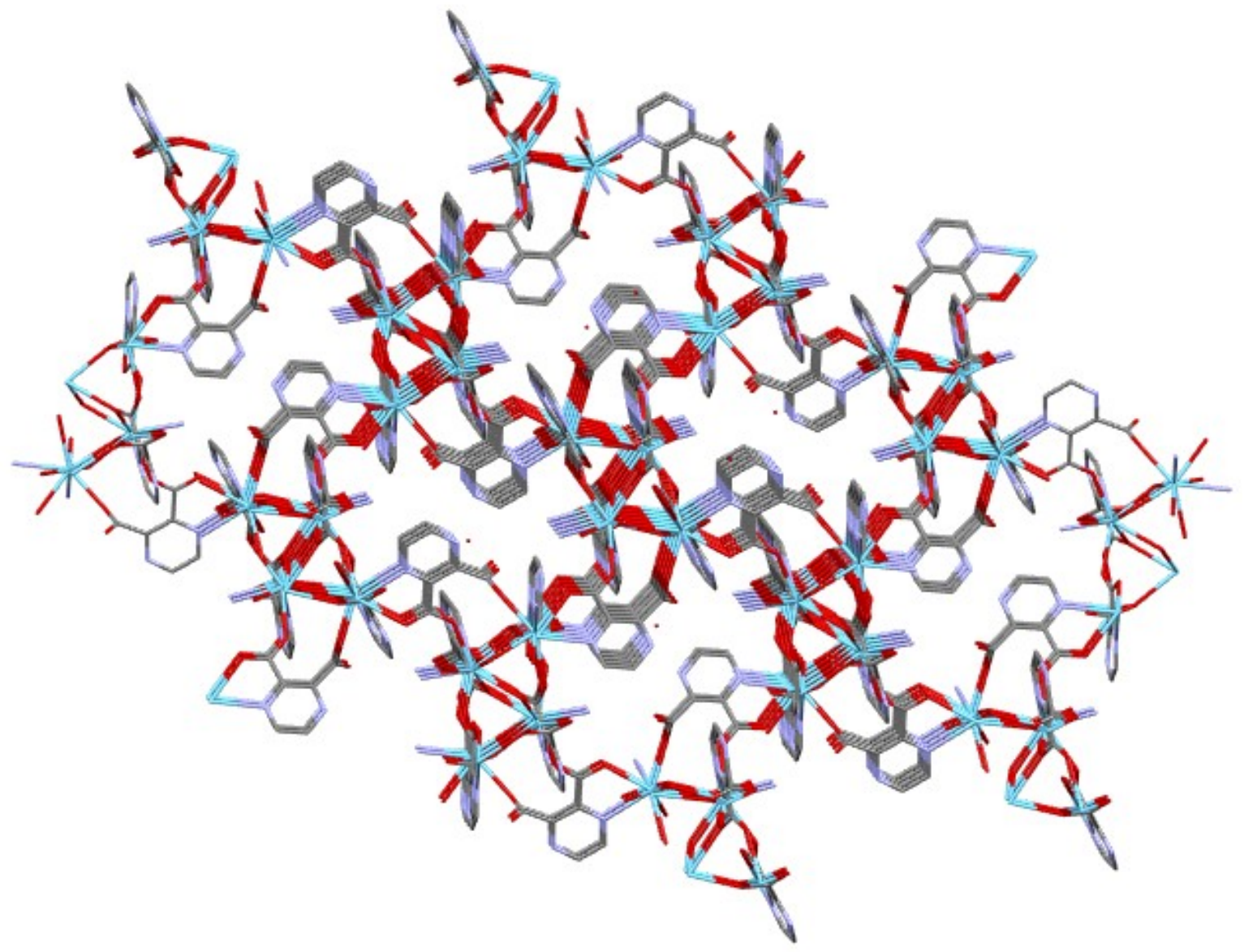

(b)

Figure 10: Coordination environment of the $\mathbf{2}$ (a) and 3D packing diagram linked by tetradentate, hexadentate, and heptadentate pzdc ligands (b). All hydrogen atoms are omitted for clarity.

\begin{tabular}{cccc}
\multicolumn{5}{c}{ Table 3. Selected bond length $[\AA]$ and bond } & angles $\left[{ }^{\circ}\right]$ for $\mathbf{2}$ \\
\hline La1-O3 & $2.450(3)$ & La1-O1 & $2.501(5)$ \\
La1-O4 & $2.561(4)$ & La1-N1 & $2.531(5)$ \\
La1-N2 & $2.767(4)$ & La1-O5 & $2.544(3)$ \\
La1-O6 & $2.577(4)$ & La1-O2 & $2.713(3)$ \\
La1-O4 & $2.625(4)$ & La2-O7 & $2.403(5)$ \\
La2-O5 & $2.699(4)$ & La2-O10 & $2.610(3)$ \\
La2-O9 & $2.502(4)$ & La2-O6 & $2.497(3)$ \\
La2-O8 & $2.509(4)$ & La1-O6 & $2.577(4)$ \\
& & & \\
O3-La1-O1 & $144.1(1)$ & O3-La1-O4 & $132.0(1)$ \\
O3-La1-N1 & $83.0(1)$ & O3-La1-N2 & $71.7(1)$ \\
O3-La1-O5 & $73.7(1)$ & O3-La1-O6 & $75.2(1)$ \\
O3-La1-O2 & $69.2(1)$ & O3-La1-O4 & $138.9(1)$ \\
O1-La1-O4 & $72.8(1)$ & O1-La1-N1 & $73.5(1)$ \\
O1-La1-N2 & $122.3(1)$ & O1-La1-O5 & $138.5(1)$ \\
O4-La1-O5 & $92.2(1)$ & N1-La1-N2 & $70.2(1)$ \\
O4-La1-O2 & $151.0(1)$ & N1-La1-O6 & $128.2(1)$ \\
\hline
\end{tabular}

\section{IR spectra}

FT-IR spectra of free ligands $\mathbf{1}$ and $\mathbf{2}$ are given in Figures S1-S3. The peaks seen in the range of $3300-3500 \mathrm{~cm}^{-1}$ are belong to $\mathrm{U}(\mathrm{O}-\mathrm{H})$ stretching vibrations of the coordinated and uncoordinated water molecules in the structures. In the IR spectrum of the 2,3-pzdc, the band at $1712 \mathrm{~cm}^{-1}$ is attributed to $\mathrm{U}(\mathrm{C}=\mathrm{O})$ stretching band (50). After coordination, this peak shifted to $1618 \mathrm{~cm}^{-1}$ (for $\mathbf{1}$ ) and $1606 \mathrm{~cm}^{-1}$ (for 2) as strong peaks in the 
spectrum of complexes. These shifts support that the oxygen atoms in carbonyl groups are coordinated to lanthanides. The symmetric stretching vibrations of $\mathrm{u}(\mathrm{C}=\mathrm{O})$ in the polymeric chain are observed at 1366 and $1363 \mathrm{~cm}^{-1}$, respectively. In the IR spectrum of the 2,3-pzdc, the band at $1687 \mathrm{~cm}^{-1}$ is attributed to $\mathrm{U}(\mathrm{C}=\mathrm{N})$ stretching band. This peak shifted to $1557 \mathrm{~cm}^{-1}$ for 2 after coordination. New bands at 442 and 434 $\mathrm{cm}^{-1}$ in the spectrum of complexes are attributed to $\mathrm{u}(\mathrm{La}-\mathrm{O})$. The coordination of the oxygen atoms to the metal ions indicates that the CPs are formed. A new and strong band at $556 \mathrm{~cm}^{-1}$ in the spectrum of $\mathbf{2}$ is attributed to $\mathrm{U}(\mathrm{La}-\mathrm{N})$ stretching vibrations (51).

\section{Thermal properties}

TG/DTG curves of $\mathbf{1}$ and $\mathbf{2}$ are given in Figures S4 and S5. Three-step mass losses are observed in the TG/DTG curve of $\mathbf{1}$. Two mass losses at around $100-300{ }^{\circ} \mathrm{C}$ temperatures are thought to belong to coordinated and uncoordinated water molecules in the structure. The final mass loss between temperatures of 357 and $600{ }^{\circ} \mathrm{C}$ is related to the degradation of organic ligands in the structure. When the TG/DTG curve of the $\mathbf{2}$ was examined, two-step mass loss occurred. The coordination polymer exhibited thermal stability up to about $150{ }^{\circ} \mathrm{C}$. The first mass loss between 150-285 ${ }^{\circ} \mathrm{C}$ belongs to the degradation of water molecules in the framework. The second mass loss at around 372-590 ${ }^{\circ} \mathrm{C}$ corresponds to the degradation of organic ligands. As seen in thermal curves, $\mathbf{2}$ is more thermally stable than $\mathbf{1}$. It is due to the fact that the uncoordinated water molecules in the structure $\mathbf{2}$ are connected to the main structure by hydrogen bonds from N1-O2W-010, O1W-042 atoms (Figures S6 and S7).

\section{PXRD patterns}

To determine the phase purities of the CPs, powder XRD analysis was performed at room temperature. For this purpose, simulated and experimental XRD results were compared. The simulated X-ray diffraction patterns were determined by Mercury diffraction-crystal module program with the help of data obtained as a result of single crystal analysis. The experimental and simulated powder XRD patterns of the synthesized compounds are given in Figure S8. These patterns were compared with each other in terms of peak positions. When the experimental and theoretical curves of the samples are examined, they are compatible, and obtained with high purity. These results are supported with high resolution microscope images.

\section{Morphologies of the CPs}

BET and FESEM analysis were performed to determine surface morphology, pore volume, and pore size of CPs. When the surface morphology of 1 was examined, it was seen that obviously the crystals have both porous structures and regional cracks in different approximations (Figure 11). The surface area of 1 was determined as $5.82 \mathrm{~m}^{2} / \mathrm{g}$ and the pore volume was $18.25 \times 10^{-3} \mathrm{~cm}^{3} / \mathrm{g}$ as a result of $B E T$ analysis. In addition, the average pore size of the crystal having mesoporous structure was calculated as $3.21 \mathrm{~nm}$ diameter.
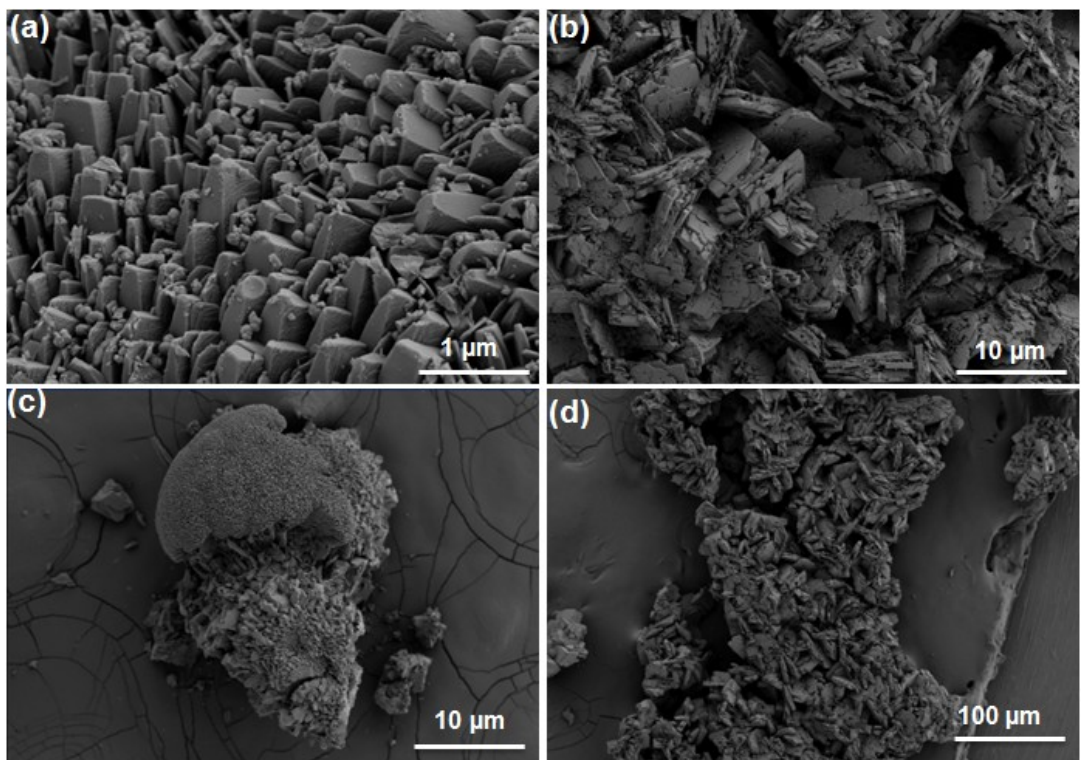

Figure 11: FESEM images of $\mathbf{1}$

When the surface morphology of $\mathbf{2}$ was examined, there are regional crystallizations in different approximations of the crystals (Figure 12). The surface area of the crystal was $6.43 \mathrm{~m}^{2} / \mathrm{g}$, and the pore volume was $6.80 \times 10^{-3} \mathrm{~cm}^{3} / \mathrm{g}$. It is also in mesoporous form due to the average pore diameter of $3.08 \mathrm{~nm}$. 

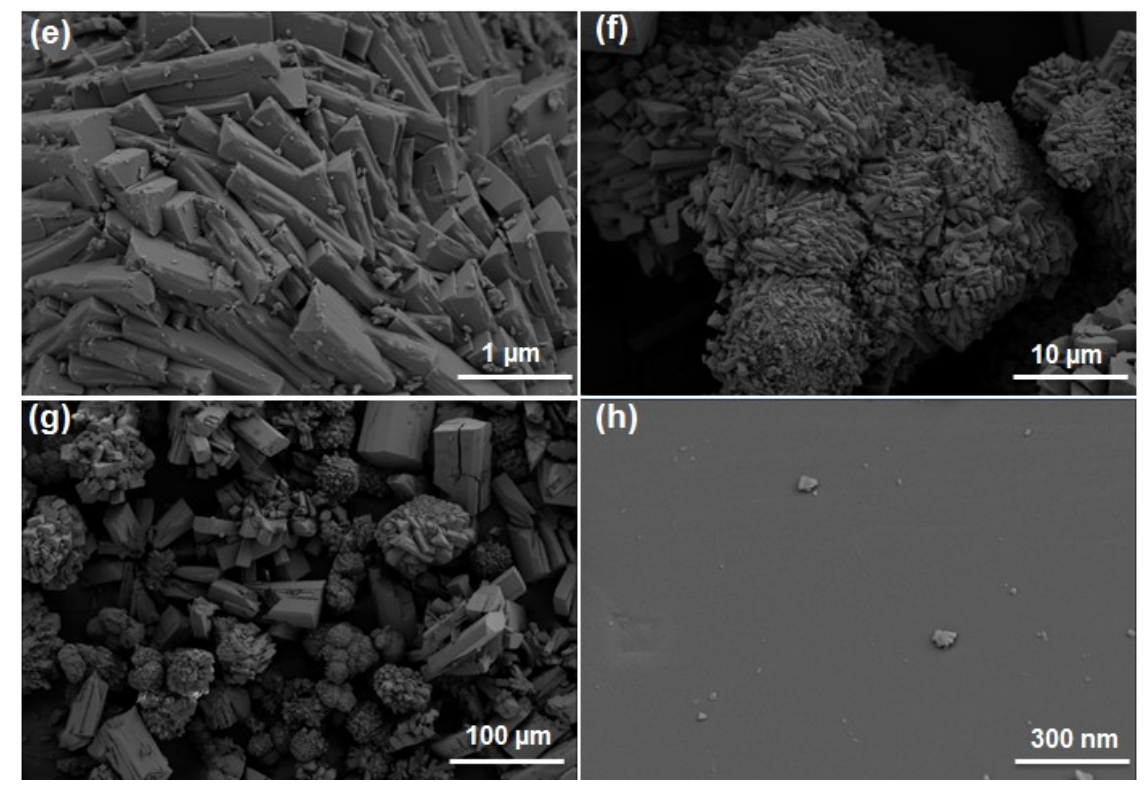

Figure 12: FESEM images of 2.

\section{Luminescence properties}

Lanthanides are of great significance for designing new luminescent materials and cause new areas of application. Narrow-band light-emitting performances of lanthanides are excellent (52). Luminescence properties of free ligand and CPs are investigated in solid state at room temperature, as shown in Figure 13. The free 2,3-pzdc acid ligand displays an emission maximum at $415 \mathrm{~nm}\left(\lambda_{\mathrm{ex}}=\right.$ $300 \mathrm{~nm}$ ), which is attributed to the $\Pi^{*}-\mathrm{n}$ transition. Bathochromic (red) shifts are observed in $\mathbf{1}$ and $\mathbf{2}$ polymers compared with the 2,3-pzdc. 1 gives a narrow and strong emission band from $505 \mathrm{~nm}$ to $520 \mathrm{~nm}$ with the maximum at $517 \mathrm{~nm}$ upon excitation at $285 \mathrm{~nm}$, and similarly $\mathbf{2}$ gives a narrow and strong emission band from $565 \mathrm{~nm}$ to $602 \mathrm{~nm}$ with the maximum at $584 \mathrm{~nm}$ upon excitation at $290 \mathrm{~nm}$. These emission values are supported by similar La(III) studies in the literature (53). According to the above results, the emission of complexes may be assigned to the ligand-to-metal-charge-transfer bands (LMCT) (54, $55)$, rather than the $n^{*}-n$ transition of the ligand. Although the polymers have the same ligand and metal, the emission values are different due to the difference in the coordination numbers and modes formed by various $\mathrm{pH}$ values. The excitation and emission values, Stokes' shifts and emitted colors of the synthesized coordination polymers are summarized in Table 4. It was observed that there was no overlap in excitation and emission values in all of the compounds and they give bands at distal wavelengths. Very large Stokes' shift values (232 $\mathrm{nm}$ for 1, $294 \mathrm{~nm}$ for 2) are observed. Large Stokes' shifts, thermal stability, brightness, and suitable material size lead to be in many different sensor applications $(56,57)$. 

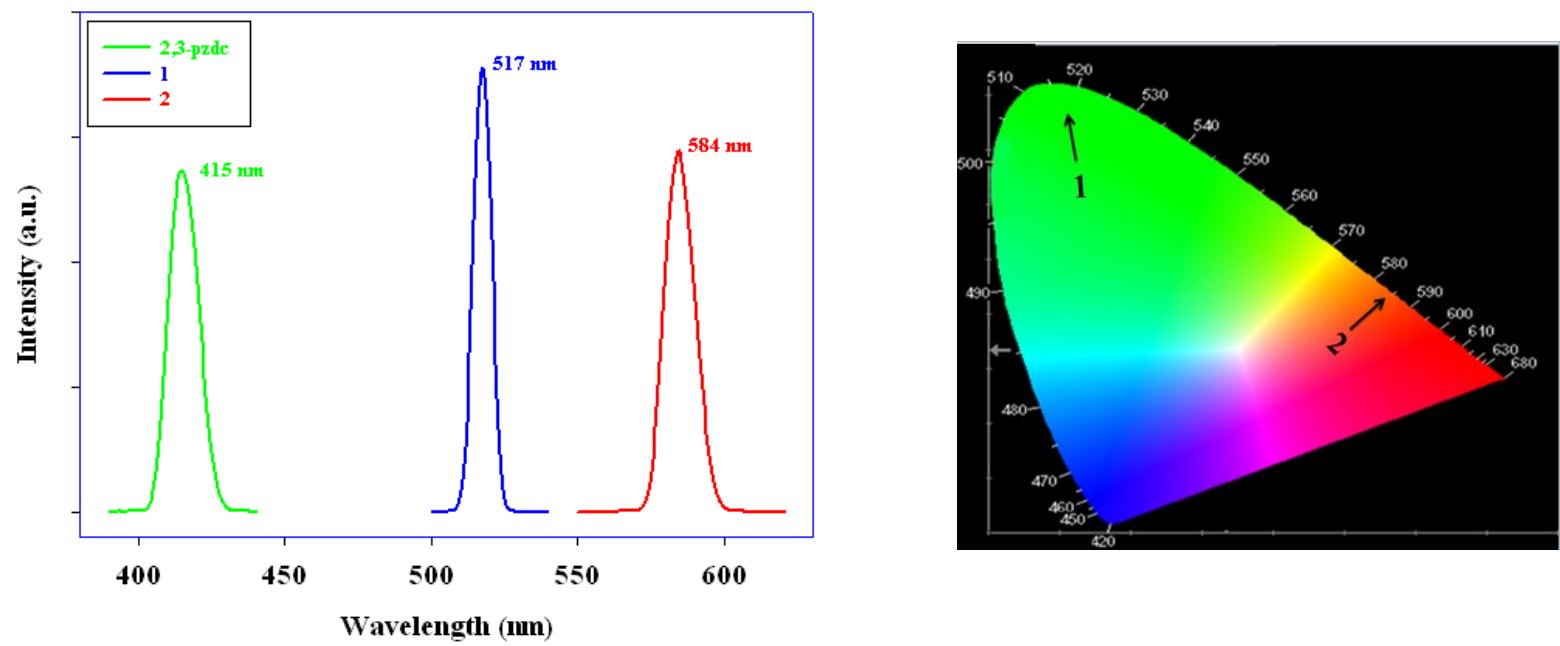

Figure 13: Solid-state emission spectra of 2,3-pzdc, chromaticity diagram of compounds $\mathbf{1}$ and $\mathbf{2}$ at room temperature.

Table 4.The luminescence results of free ligand and coordination polymers.

\begin{tabular}{lcccc}
\hline Compounds & $\begin{array}{c}\text { Excitation } \\
(\boldsymbol{\Lambda}, \mathbf{n m})\end{array}$ & $\begin{array}{c}\text { Emission } \\
(\boldsymbol{\Lambda}, \mathbf{n m})\end{array}$ & Stokes' Shift $\mathbf{( n m )}$ & $\begin{array}{c}\text { Emitted } \\
\text { Color }\end{array}$ \\
\hline & & & & \\
$2,3-p z d c$ & 300 & 415 & 115 & - \\
$\mathbf{1}$ & 285 & 517 & 232 & Green \\
$\mathbf{2}$ & 290 & 584 & 294 & Yellow \\
\hline
\end{tabular}

\section{Electrical conductivity}

Liquid based electrolytes are widely used as batteries and supercapacitors. Moreover, because of their high thermal stability, easier processability, and mechanical properties, inorganic-organic solid polymers attract more attention than others. Therefore, solid polymer conductors (organic or organic-inorganic) have been proposed as an alternative to liquid based electrolytes. Because of the facile synthesis of CPs by hydrothermal method, and having high thermal stability, we aimed to examine their electrical conductivity properties in a solid phase. Crystal samples of CPS were compressed under 12 tons of pressure as a solid phase. Their thickness $(0.274 \mathrm{~mm}$ for 1; $0.435 \mathrm{~mm}$ for 2 ) and diameters $(12 \mathrm{~mm}$ ) were measured by using digital micrometer. Solid electrical conductivity measurements were performed at room temperature. Electrical conductivity values of the CPs were measured by four-point probe technique. In order to obtain the most accurate results, the conductivity values were measured in five parallel measurements. The highest electrical conductivity was exhibited by $\mathbf{1}$ with $3.45 \times 10^{-6} \mathrm{~S} / \mathrm{cm}$ at ambient temperature. 2 showed the maximum conductivity of $2.08 \times 10^{-6}$ $\mathrm{S} / \mathrm{cm}$ at $25^{\circ} \mathrm{C}$. Both mesoporous samples showed very close electrical conductivity values. Due to having different framework structures, 1 exhibited slightly more conductivity values than that of $\mathbf{2}$. The conductivity range of the conducting polymers is between $10^{-12}$ and $10^{4} \mathrm{~S} / \mathrm{cm}$, while the electro active polymeric composite ranges from $10^{-8}$ to $10^{3}$ $\mathrm{S} / \mathrm{cm}$. However, the semiconductor range is between $10^{-8}$ and $10 \mathrm{~S} / \mathrm{cm}$ (58). In our study, mesoporous CPs showed conductivity values at $10^{-}$ ${ }^{6} \mathrm{~S} / \mathrm{cm}$. According to the literature, the synthesized polymers can be used as semiconducting materials in solid phase. These materials have found a wide range of applications because of their low cost, compactness, power efficiency and reliability.

\section{CONCLUSION}

In summary, three dimensional La(III) coordination polymers based on multifunctional 2,3-pzdc acid were synthesized under subcritical conditions in different $\mathrm{pH}$ values and were fully characterized. It is noteworthy that 2,3-pzdc acid in the frameworks have different coordination modes. Therefore, it is found that the $\mathrm{pH}$ value of the solution plays an important role in their coordination modes and frameworks under hydrothermal conditions. $\mathbf{1}$ and $\mathbf{2}$ show good electrical conductivity values of $3.45 \times 10^{-6}$ and $2.08 \times 10^{-6} \mathrm{~S} / \mathrm{cm}$ at room temperature, respectively. Moreover, the compounds have thermal stability up to $150{ }^{\circ} \mathrm{C}$. It is foreseen that the obtained semiconductor CPs can be employed in the manufacture of various kinds of electronic devices, including integrated circuits, transistors and diodes. Photoluminescent spectra of $\mathbf{1}$ and $\mathbf{2}$ 
showed that CPs are the potential luminescent materials at the maximum emission 517 and 584 $\mathrm{nm}$ with sharp and narrow bands. Because of their very large Stokes shifts and low cost, the synthesized CPs may find applications in different sensor applications and light-emitting devices.

\section{ACKNOWLEDGEMENT}

The authors gratefully acknowledge financial support from the Research Unit of Çukurova University (Grant No. FEF2013D5).

\section{REFERENCES}

1. Guillerm V, Kim D, Eubank JF, Luebke R, Liu X, Adil K, Lah MS, Eddaoudi M. A supermolecular building approach for the design and construction of metal-organic frameworks. Chemical Society Reviews 2014; 43: 6141-6172. DOI: $10.1039 / c 4 c s 00135 d$

2. Zhou $X$, Liu $P$, Huang $W-H$, Kang $M$, Wang $Y-Y$, Shi Q-Z. Solvents influence on sizes of channels in three fry topological Mn(II)-MOFs based on metalcarboxylate chains: syntheses, structures and magnetic properties. CrystEngComm 2013; 15: 8125-8133. DOI: $10.1039 /$ C3CE41120F

3. Wang $P$, Fan $R-Q$, Liu $X-R$, Wang $L-Y$, Yang $Y-L$, Cao W-W, Yang B, Hasi W, Su Q, Mu Y.

Two-/three-dimensional open lanthanide-organic frameworks containing rigid/flexible dicarboxylate ligands: synthesis, crystal structure and photoluminescent properties. CrystEngComm 2013; 15: 1931-1949. DOI: 10.1039/c3ce26684b

4. Dhakshinamoorthy A, Alvaro M, Garcia H. Commercial metal-organic frameworks as heterogeneous catalysts. Chemical Communications 2012; 48: 11275-11289. DOI: $10.1039 / \mathrm{c} 2 \mathrm{cc} 34329 \mathrm{k}$

5. Nguyen LTL, Le KKA, Truong HX, Phan NTS. Metal-organic frameworks for catalysis: the Knoevenagel reaction using zeolite imidazolate framework ZIF-9 as an efficient heterogeneous catalyst. Catalysis Science \& Technology 2012; 2: 521-528. DOI: 10.1039/c1cy00386k

6. Tan Y-X, He Y-P, Zhang J. Cluster-Organic Framework Materials as Heterogeneous Catalysts for High Efficient Addition Reaction of Diethylzinc to Aromatic Aldehydes. Chemistry of Materials 2012; 24: 4711-4716. DOI: $10.1021 / \mathrm{cm} 302953 x$

7. Tian D, Li Y, Chen R-Y, Chang Z, Wang G-Y, Bu $\mathrm{X}-\mathrm{H}$. A luminescent metal-organic framework demonstrating ideal detection ability for nitroaromatic explosives. Journal of Materials
Chemistry A 2014; 2: 1465-1470. DOI: 10.1039/c3ta13983b

8. Guo Y, Feng X, Han T, Wang S, Lin Z, Dong Y, Wang $B$. Tuning the Luminescence of MetalOrganic Frameworks for Detection of Energetic Heterocyclic Compounds. Journal of the American Chemical Society 2014; 136: 15485-15488. DOI: $10.1021 / j a 508962 \mathrm{~m}$

9. Kim TK, Lee JH, Moon D, Moon HR. Luminescent Li-Based Metal-Organic Framework Tailored for the Selective Detection of Explosive Nitroaromatic Compounds: Direct Observation of Interaction Sites. Inorganic Chemistry 2012; 52: 589-595. DOI: $10.1021 /$ ic3011458

10. Gándara F, Furukawa H, Lee S, Yaghi OM. High Methane Storage Capacity in Aluminum MetalOrganic Frameworks. Journal of the American Chemical Society 2014; 136: 5271-5274. DOI: 10.1021/ja501606h

11. Peng $Y$, Krungleviciute V, Eryazici I, Hupp JT, Farha OK, Yildirim T. Methane Storage in MetalOrganic Frameworks: Current Records, Surprise Findings, and Challenges. Journal of the American Chemical Society 2013; 135: 11887-11894. DOI: $10.1021 / j a 4045289$

12. Li Y-W, Li J-R, Wang L-F, Zhou B-Y, Chen Q, $\mathrm{Bu} \mathrm{X}-\mathrm{H}$. Microporous metal-organic frameworks with open metal sites as sorbents for selective gas adsorption and fluorescence sensors for metal ions. Journal of Materials Chemistry A 2013; 1: 495-499. DOI: 10.1039/c2ta00635a

13. Bloch ED, Hudson MR, Mason JA, Chavan S, Crocellà V, Howe JD, Lee K, Dzubak AL, Queen WL, Zadrozny JM, Geier SJ, Lin L-C, Gagliardi L, Smit B, Neaton JB, Bordiga S, Brown CM, Long JR.

Reversible CO Binding Enables Tunable $\mathrm{CO} / \mathrm{H} 2$ and CO/N2 Separations in Metal-Organic Frameworks with Exposed Divalent Metal Cations. Journal of the American Chemical Society 2014; 136: 1075210761. DOI: $10.1021 /$ ja505318p

14. Dou Z, Yu J, Cui Y, Yang Y, Wang Z, Yang D, Qian G. Luminescent Metal-Organic Framework Films As Highly Sensitive and Fast-Response Oxygen Sensors. Journal of the American Chemical Society 2014; 136: 5527-5530. DOI: $10.1021 / j a 411224 j$

15. Cunha D, Ben Yahia M, Hall S, Miller SR, Chevreau $H$, Elkaïm E, Maurin G, Horcajada P, Serre C. Rationale of Drug Encapsulation and Release from Biocompatible Porous Metal-Organic Frameworks. Chemistry of Materials 2013; 25: 2767-2776. DOI: $10.1021 / \mathrm{cm} 400798 p$ 
16. Seetharaj R, Vandana PV, Arya P, Mathew S. Dependence of solvents, $\mathrm{pH}$, molar ratio and temperature in tuning metal organic framework architecture. Arabian Journal of Chemistry 2016; 12: 295-315. DOI: 10.1016/j.arabjc.2016.01.003

17. Li P-Z, Wang X-J, Li Y, Zhang Q, Tan RHD, Lim WQ, Ganguly R, Zhao Y. Co(II)-tricarboxylate metal-organic frameworks constructed from solvent-directed assembly for $\mathrm{CO} 2$ adsorption. Microporous and Mesoporous Materials 2013; 176: 194-198. DOI: 10.1016/j.micromeso.2013.03.052

18. Sun F, Zhu G. Solvent-directed synthesis of chiral and non-centrosymmetric metal-organic frameworks based on pyridine-3,5-dicarboxylate. Inorganic Chemistry Communications 2013; 38: 115-118. DOI: $10.1016 / j$.inoche.2013.10.018

19. Liu T, Luo D, Xu D, Zeng H, Lin Z. Solvent induced structural variation in magnesium carboxylate frameworks. Inorganic Chemistry Communications 2013; 29: 110-113. DOI: 10.1016/j.inoche.2012.12.017

20. Chen L, Jia $H-Y$, Hong $X-J$, Chen D-H, Zheng Z$P$, Jin $H-G$, Gu Z-G, Cai $Y-P$.

Construction of one $\mathrm{pH}$-independent 3-D pillarlayer lead-organic framework containing tetrazole1 -acetic acid. Inorganic Chemistry Communications 2013; 27: 22-25. DOI:

10.1016/j.inoche.2012.10.010

21. Li S-L, Tan K, Lan Y-Q, Qin J-S, Li M-N, Du D$\mathrm{Y}$, Zang H-Y, Su Z-M. pH-Dependent Binary MetalOrganic Compounds Assembled from Different Helical Units: Structural Variation and Supramolecular Isomers. Crystal Growth \& Design 2010; 10: 1699-1705. DOI: $10.1021 / \mathrm{cg} 9012763$

22. Gabriel C, Perikli M, Raptopoulou CP, Terzis A, Psycharis V, Mateescu C, Jakusch T, Kiss T, Bertmer M, Salifoglou A. pH-Specific Hydrothermal Assembly of Binary and Ternary $\mathrm{Pb}$ (II)-(O,NCarboxylic Acid) Metal Organic Framework Compounds: Correlation of Aqueous Solution Speciation with Variable Dimensionality Solid-State Lattice Architecture and Spectroscopic Signatures. Inorganic Chemistry 2012; 51: 9282-9296. DOI: $10.1021 / \mathrm{ic} 300850 \mathrm{~g}$

23. Ollivier PJ, DeBoard JRD, Zapf PJ, Zubieta J, Meyer LM, Wang C, Mallouk TE, Haushalter RC. Hydrothermal synthesis and crystal structures of two novel vanadium oxides containing interlamellar transition metal complexes. Journal of Molecular Structure 1998; 470: 49-60. DOI: 10.1016/S00222860(98)00469-4

24. Kim D, Song X, Yoon JH, Lah MS. 3,6Connected Metal-Organic Frameworks Based on
Triscarboxylate as a 3-Connected Organic Node and a Linear Trinuclear $\mathrm{Co3}(\mathrm{COO}) 6$ Secondary Building Unit as a 6-Connected Node. Crystal Growth \& Design 2012; 12: 4186-4193. DOI: $10.1021 / \mathrm{cg} 300686 n$

25. Darling K, Ouellette W, Prosvirin A, Walter S, Dunbar KR, Zubieta J. Hydrothermal synthesis and structures of materials of the $\mathrm{M}(\mathrm{II}) /$ tetrazole/sulfate family $(\mathrm{M}(\mathrm{II})=\mathrm{Co}, \mathrm{Ni}$; tetrazole $=3$ - and 4-pyridyltetrazole and pyrazinetetrazole). Polyhedron 2013; 58: 18-29. DOI: $10.1016 /$ j.poly.2012.07.043

26. Sun $Y-X$, Sun $W-Y$. Influence of temperature on metal-organic frameworks. Chinese Chemical Letters 2014; 25: 823-828. DOI:

10.1016/j.cclet.2014.04.032

27. Liu G-X, Xu H, Zhou H, Nishihara S, Ren X-M. Temperature-induced assembly of MOF polymorphs: Syntheses, structures and physical properties. CrystEngComm 2012; 14: 1856-1864. DOI: $10.1039 / \mathrm{c} 1 \mathrm{ce} 05369 \mathrm{~h}$

28. Calderone PJ, Banerjee D, Plonka AM, Kim SJ, Parise JB. Temperature dependent structure formation and photoluminescence studies of a series of magnesium-based coordination networks. Inorganica Chimica Acta 2013; 394: 452-458. DOI: $10.1016 /$ j.ica.2012.08.033

29. Mahata P, Prabu M, Natarajan S. Role of Temperature and Time in the Formation of Infinite -M-O-MLinkages and Isolated Clusters in MOFs: A Few Illustrative Examples. Inorganic Chemistry 2008; 47: 8451-8463. DOI: $10.1021 /$ ic800621q

30. Wenkin M, Touillaux R, Devillers M. Bismuth derivatives of 2,3-dicarboxypyrazine and 3,5dicarboxypyrazole as precursors for bismuth oxide based materials. New Journal of Chemistry 1998; 22: 973-976. DOI:10.1039/A801161C

31. Xu H, Ma H, Xu M, Zhao W, Guo B. catenaPoly[[[diaquairon(II)]- $\mu$-pyrazine-2,3dicarboxylato] dihydrate]. Acta Crystallographica Section E Structure Reports Online 2007; 64: m104-m104. Doi: 10.1107/S1600536807064501

32. Liu H-Y, Wang H-Y, Shi Y-H. Pyrazine-2,3dicarboxylate-bridged polymeric and dinuclear complexes involving decameric water clusters. Journal of Coordination Chemistry 2011; 64: 28592868. DOI: $10.1080 / 00958972.2011 .608161$

33. Okubo T, Kondo M, Kitagawa S. Synthesis, Structure, and Magnetic Properties of OneDimensional Copper(II) Coordination Polymer, $\{[\mathrm{Cu}$ (pyrazine-2,3-dicarboxylate) $(\mathrm{H} 2 \mathrm{O}) 2] 2 \mathrm{H} 2 \mathrm{O}\} \mathrm{n}$. 
Synthetic Metals 1997; 85: 1661-1662. DOI: 10.1016/S0379-6779(97)80386-4

34. Beobide G, Castillo O, Luque A, GarciaCouceiro U, Garcia-Teran JP, Roma 'n P. Supramolecular Architectures and Magnetic Properties of Coordination Polymers Based on Pyrazinedicarboxylato Ligands Showing Embedded Water Clusters. Inorganic Chemistry 2006; 45: 5367-5382. DOI: 10.1021/ic060221r

35. Yeşilel $O Z$, Mutlu $A$, Büyükgüngör O. Novel dinuclear and polynuclear copper(II)-pyrazine-2,3dicarboxylate supramolecular complexes with 1,3propanediamine, $\mathrm{N}, \mathrm{N}, \mathrm{N}^{\prime}, \mathrm{N}^{\prime}-$

tetramethylethylenediamine and 2,2'-bipyridine. Polyhedron 2009; 28: 437-444. DOI:

$10.1016 /$ j.poly.2008.11.044

36. Yang K, Luo J-H, Liu Z-H. Synthesis, structures and luminescent property of two lanthanon complexes assembled from 2,3-

pyrazinedicarboxylic acid and ammonia. Inorganica Chimica Acta 2012; 391: 206-209. DOI:

10.1016/j.ica.2012.04.040

37. Zou J, Xu Z, Chen W, Lo KM, You X. Synthesis, structure and magnetic properties of new polymeric compounds containing manganese(II)Pzdc (PzdcH : 2,3-Pyrazinedicarboxylic acid). Polyhedron 1999; 18: 1507-1512. DOI: 10.1016/S0277-5387(99)00019-4

38. Yeşilel $O Z$, Mutlu $A$, Büyükgüngör $O$. A new coordination mode of pyrazine-2,3-dicarboxylic acid and its first monodentate complexes: Syntheses, spectral, thermal and structural characterization of $[\mathrm{Cu}($ pzdca $)(\mathrm{H} 2 \mathrm{O})(\mathrm{en}) 2] \cdot \mathrm{H} 2 \mathrm{O}$ and [Cu(pzdca)(H2O)(dmpen)2]. Polyhedron 2008; 27: 2471-2477. DOI: 10.1016/j.poly.2008.04.046

39. Li X-H, Shi Q, Hu M-L, Xiao H-P. A crossing double chain $\{[\mathrm{Cu}(\mathrm{PZDC} 2] \cdot 3(\mathrm{H} 2 \mathrm{O}) \cdot 2(\mathrm{IDZC})\} \mathrm{n}$ (H2PZDC =2,3-pyrazinedicarboxylic acid, IDZC=imidazole cation). Inorganic Chemistry Communications 2004; 7: 912-914.

DOI: $10.1016 /$ j.inoche.2004.05.017

40. Bayon JC, Net G, Real J, Rasmussen PG. Synthesis and reactivity of rhodium(I) and iridium(I) complexes of the dianions of 2,3pyrazinedicarboxylic and 2,5-pyrazinedicarboxylic acid. Journal of Organometallic Chemistry 1990; 385: 409-415. DOI: $10.1016 / 0022-$

$328 \times(90) 85012-\mathrm{N}$

41. Wenkin M, Devillers M, Tinant B, Deelercq J-P. Diammine(pyrazine-2,3-dicarboxylato-

$\mathrm{N}, \mathrm{O}$ )palladium(II): synthesis, crystal structure, spectroscopic and thermal properties. Inorganica
Chimica Acta 1997; 258: 113-118. DOI: $10.1016 /$ S0020-1693(96)05533-8

42. Yin H, Liu S-X. Syntheses, crystal structures and photoluminescence of three coordination polymers with 2,3-pyrazinedicarboxylic acid and Ndonor ligands. Polyhedron 2007; 26: 3103-3111. DOI: $10.1016 /$ j.poly.2007.02.011

43. Yang L-R, Song S, Zhang W, Zhang H-M, Bu ZW, Ren T-G. Synthesis, structure and luminescent properties of neodymium(III) coordination polymers with 2,3-pyrazinedicarboxylic acid. Synthetic Metals 2011; 161: 647-654. DOI: 10.1016/j.synthmet.2010.12.005

44. SMART DCS, version 5.630, Bruker-AXS Inc., Madison, WI, 1997-2002.

45. SAINT PLUS DRS, version 6.45A, Bruker-AXS Inc., Madison, WI, 1997-2002.

46. Sheldrick GM, University of Göttingen, Göttingen, Germany, 1996.

47. SHELXTL PC v, Bruker-AXS Inc., Madison, WI, 2002.

48. Yang Q, Xie G, Wei Q, Chen S, Gao S. Structures and standard molar enthalpies of formation of a series of $\mathrm{Ln}$ (III)-Cu(II) heteronuclear compounds with pyrazine-2,3dicarboxylic acid. Journal of Solid State Chemistry 2014; 215: 26-33. DOI:

$10.1016 / j . j s s c .2014 .03 .021$

49. Zhuang G, Chen W, Zeng G, Wang J, Chen W. Position of substituent dependent dimensionality in $\mathrm{Ln}-\mathrm{Cu}$ heterometallic coordination polymers.

CrystEngComm 2012; 14: 679-683. DOI: 10.1039/ c1ce05864a

50. Beaula TJ, Joe IH, Rastogi VK, Jothy VB. Chemical Computations and Vibrational Spectral Studies of 2,3-Pyrazinedicarboxylic Acid. Materials Today: Proceedings 2015; 2: 977-981. DOI: 10.1016/j.matpr.2015.06.020

51. Sriramula VSB, Katreddi HR. Rare Earth Nitrate Complexes with an ONO Schiff Base Ligand:Spectral, Thermal, Luminescence and Biological Studies. Iranian Journal of Chemistry and Chemical Engineering 2017; 36: 101-109.

52. Chen $Y$, Li H, Yue B, Liu Y, Chu H, Zhao Y. Synthesis, characterization and luminescent property of metal-ion-doped terbium complexes of 2,3-Pyrazinedicarboxylate. Journal of Luminescence 2012; 132: 1414-1419. DOI: $10.1016 /$ j.jlumin.2012.01.030 
53. Zhao Q, Liu X-M, Li H-R, Zhang Y-H, Bu X-H. High-performance fluorescence sensing of lanthanum ions (La3+) by a polydentate pyridylbased quinoxaline derivative. Dalton Transactions 2016; 45: 10836-10841. DOI: $10.1039 / \mathrm{c} 6 \mathrm{dt} 01161 \mathrm{f}$

54. Yin H, Liu S. Copper and zinc complexes with 2,3-pyridinedicarboxylic acid or 2,3-

pyrazinedicarboxylic acid: Polymer structures and magnetic properties. Journal of Molecular Structure 2009; 918: 165-173. DOI:

10.1016/j.molstruc.2008.07.033

55. Mahata P, Ramya KV, Natarajan S. Synthesis, structure and optical properties of rare-earth benzene carboxylates. Dalton Transactions 2007: 4017-4026. DOI: 10.1039/b706363f
56. Santiago-González B, Vázquez-Vázquez C, Blanco-Varela MC, Gaspar Martinho JM, RamalloLópez JM, Requejo FG, López-Quintela MA. Synthesis of water-soluble gold clusters in nanosomes displaying robust photoluminescence with very large Stokes shift. Journal of Colloid and Interface Science 2015; 455: 154-162. DOI: $10.1016 /$ j.jcis. 2015.05 .042

57. Raj PJ, Bahulayan D. "MCR-Click" synthesis of coumarin-tagged macrocycles with large Stokes shift values and cytotoxicity against human breast cancer cell line MCF-7. Tetrahedron Letters 2017; 58: 2122-2126. DOI: 10.1016/j.tetlet.2017.04.052

58. Kaur G, Adhikari R, Cass P, Bown M, Gunatillake P. Electrically conductive polymers and composites for biomedical applications. RSC Advances 2015; 5: 37553-37567. DOI: $10.1039 / \mathrm{c} 5 \mathrm{ra0} 1851 \mathrm{j}$ 